\title{
Interrogating the relationship between poverty, attainment and mental health and wellbeing: the importance of social networks and support - a Scottish case study
}

\begin{abstract}
The poverty-related attainment gap is an internationally recognised problem. It resides within a culture of performativity in which international comparators, underpinned by neo-liberal ideology, drive national policy. This conceptual paper interrogates the relationship between poverty, attainment and children's mental health and wellbeing to inform public policy and practice in Scotland and beyond. A key theme identified from the analysis of the literature is the nature, quality and strength of social and support networks around schools, families and children. This is contextualised within a discussion of the nature of childhood poverty and mental health in children in Scotland and the response of the Scottish Government. A focus on educational policy and schools alone will not in itself address the poverty-related attainment gap. What is required is an holistic focus on public policy, informed by interdisciplinary research, and a focus on building a strong infrastructure of support around schools, families and communities.
\end{abstract}

\section{Keywords}

Poverty, attainment, mental health and wellbeing, policy, social support, social networks

\section{Introduction}

Every child has a fundamental right to education, and must be given the opportunity to achieve and maintain an acceptable level of learning.

Salamanca Statement 2 (United Nations, 1994)

In Scotland, all children have an entitlement to education but this does not mean that they are equally placed to take advantage of what education has to offer. Across

Europe, the USA and beyond, the degree to which children are living in equitable societies varies to a significant extent, impacting on educational outcomes, other indicators of wellbeing and life long chances (OECD, 2018a, 2018b; Putnam, 2015; Wilkinson \& Pickett, 2018).

Discussions of the relationship between poverty and attainment conceal, as an explanation, the significance of mental health and wellbeing. They say little about the 
importance of social networks and support. They generally fail to problematise the essential relationship between attainment, mental health and wellbeing, and they underplay the nature of poverty and the varying ways in which it manifests itself in Scotland. Yet, this social and political contextualisation is vital to our understanding of this complex issue.

The aim of this conceptual paper is to interrogate the relationship between poverty, attainment and children's mental health and wellbeing to gain an understanding of the nature of the poverty-related attainment gap in order to inform policy and practice internationally and in Scotland. A key theme identified from the analysis of the literature is the nature, quality and strength of social and support networks around schools, families, children and young people. This theme is the principal focus of the paper. It is contextualised within an initial discussion of the macrosystem which serves as both the context for and a mediator of the triadic relationship.

\section{Theoretical perspectives}

Given the complexity of the issue in question, there is no single lens through which it can be understood. It requires a multi-disciplinary focus and can be approached from a range of theoretical perspectives. The discussion to follow outlines key aspects of social capital theory, ecological systems theory and an ecological perspective on resilience.

\section{Social Capital Theory}

Those who possess forms of economic, cultural ${ }^{\mathrm{ii}}$ and social capital are more likely to achieve academic success (Rogošić \& Baranović 2016). Peer social capital contributes towards the academic resilience of children living in poverty, achieved 
through the cultivation of pro-academic behaviours, non-academic peer support (advice, encouragement) and reciprocal academic support (Williams, Bryan, Morrison, \& Scott, 2017).

Since the initial work of Bourdieu, Coleman and Putnam, the concept has been strongly theorised but its applications to education are less certain (Rogošić \& Baranović 2016). It functions as an explanatory concept through which to explore social processes and practices and operates within the spaces between the micro- and macro-level (McGonigal et al., 2005), thus relating to ecological understandings, as outlined in the discussion to follow. The concept has been described as 'chameleon like' - there is no single definition which captures its complexity (McGonigal et al., 2005). For Bourdieu, social capital is a more individualistic concept comprising social obligations (connections) which, in certain circumstances, are convertible into other forms of capital, operating through social fields (the social arenas in which this takes place). For Coleman and Putnam, it is more about networking to facilitate community based-action and promoting wellbeing - social capital is relational, focussing on human connectedness, trust and reciprocity (Deuchar, 2009; Rogošić \& Baranović 2016). Putnam distinguishes between three types of social capital - bonding (between people of similar social strata), bridging (across social divisions) and linking (a form of bridging enabling people to form alliances with authoritative and powerful organisations and individuals) (McGonigal et al., 2005). For the purposes of this study, Putnam's conception of social capital is the most apt.

\section{Ecological Systems Theory}

Bronfenbrenner proposed that children constantly grow, change, engage with multiple systems, and are active participants in their development as a result of reciprocal interactions between individual characteristics and their environments.

Brewin \& Statham, 2011: 369 
Bronfenbrenner's bio-ecological systems theory provides a valuable lens through which to understand the complex interactions between the microsystem (the characteristics of the child interacting with their immediate environment - the experience and agency of the child); the exosystem (the social system which impacts indirectly on the child); the mesosystem which links both of the aforementioned through the various settings in which people associated with the child interact; and the macrosystem, the culture or society that frames the structures and relationships among the systems, operating within the chronosystem (in time and space) (Bronfenbrenner \& Morris, 2006; Newman \& Newman, 2016). It can be seen that the quality, strength and nature of the networks with which the child interacts at the various levels, whether directly or indirectly, are important aspects of ecological theory, linking to social capital, as outlined above.

\section{An Ecological Perspective on Resilience}

Building on the initial work of Garmezy (1971), there is a significant literature which focuses on the concept of resilience in explaining why some children appear to succeed despite the odds whilst others do not (for example, Jindal-Snape and Miller 2008, Rutter 2012). Fostering resilience in children and young people and exposing them to a range of protective factors is often advanced as a way of counteracting the negative influences in children's lives (García-Moya, Brooks, Morgan, \& Moreno, 2015; McLure, Gilligan, \& Smith, 2015). Olsson, Bond, Burns, Vella-Brodrick, and Sawyer (2003) posit that it is how both protective and risk factors in the life of the child interact with each other at the level of the individual, the family and society which determines the degree to which the child may, or may not, exhibit characteristics associated with resilience, bringing an ecological, rather than an individual, perspective to the frame. Mowat (2015) adds a political dimension and 
argues that it is not just the interaction of the child with their environment which is of the essence but how the child rationalises their experiences. Multiple risk (or protective) factors if experienced cumulatively can combine together to exert a more powerful effect than a single life-event (Olsson et al., 2003).

Reflecting on the above theoretical perspectives, while they are all distinctive in their own right, what they have in common is that they are all explanatory frameworks which are not based on deficit understandings of communities, families and children but seek to explore the complexity of people's lives through different, but complementary, lenses.

\section{Research Questions}

1. What is the relationship between attainment, poverty and children's mental health and wellbeing as far as can be ascertained?

2. What are the variables that impact on the aforementioned relationships and the risk and protective factors at the individual, social, societal and political levels which interact with one another to shape the subjective experience of the child or young person?

3. What are the implications of the above for Scottish government policy and informing education systems globally?

\section{Methodology}

This is a conceptual paper, exploratory in nature which seeks relationships, connections and meanings. It is not empirical but it serves to provide a solid base for empirical work in the future and to identify future avenues of exploration. It does not set out to provide a comprehensive and broad understanding of a field of enquiry (as would be the case in a traditional (scoping) review). Nor does it set out to gather, 
synthesise and appraise the findings of a bounded field of enquiry (as would be the case in a systematic literature review).

It has been argued that systematic reviews are not always appropriate in the social sciences when undertaking multidisciplinary enquiry (Jesson, Matheson, \& Lacey, 2011), as is the case in this specific study. The analysis draws on an extensive range of literature, a sub-set of which is represented within this paper: - journal articles; policy documentation; statistical data; reports from a wide range of international and national organisations, including the $3^{\text {rd }}$ sector; webpages (eg. NHS; Education Scotland); and media reports.

A systematic approach was adopted in taking the study forward in order to minimise subjective bias and to ensure trustworthiness in approach but without the rigidity often associated with a systematic literature review. The study is guided by a clear set of research questions to inform the literature selected; criteria were identified to assist in the identification of the literature; and the literature was carefully documented and a series of templates created to sort, classify and analyse it, acting as an audit trail for the researcher.

\section{Selecting the Literature}

The literature was selected to illuminate three key relationships as illustrated in Figure 1. 


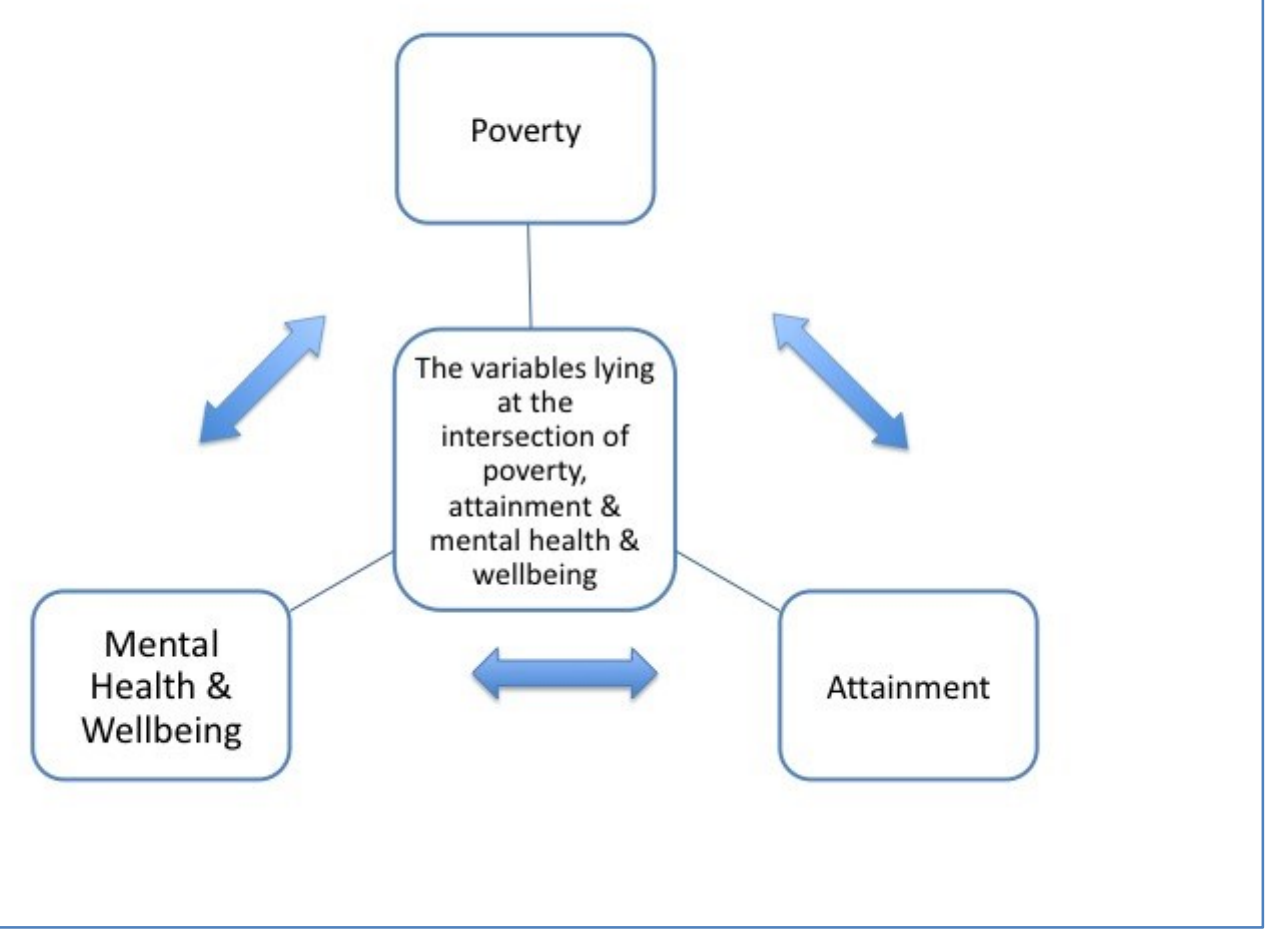

Figure 1: Representation of the triadic relationships and the variables lying at the intersection

The criteria adopted to select the literature are set out in Table 1.

\begin{tabular}{|c|c|}
\hline Relevance & $\begin{array}{l}\text { The degree to which the source informs the research questions } \\
\text { Sources which illuminate one or more of the triadic relationships } \\
\text { Sources which may focus on only one of the three areas but which provide } \\
\text { valuable contextual information } \\
\text { Sources which provide important contextual background relating to policy and } \\
\text { broader issues which impact on the issue in question }\end{array}$ \\
\hline Reliability & $\begin{array}{l}\text { The degree to which the source can be regarded as trustworthy } \\
\text { Peer-reviewed journals } \\
\text { Research monographs by respected authors } \\
\text { Documents from reliable agencies such as UNICEF, OECD, Government Agencies } \\
\text { and respected } 3^{\text {rd }} \text { sector organisations such as the Joseph Rowntree Foundation } \\
\text { Media reports from sources such as the BBC, the Guardian (where possible these } \\
\text { were traced to source) }\end{array}$ \\
\hline Locus & $\begin{array}{l}\text { Where the literature is situated in terms of place } \\
\text { Scottish } \\
\text { International to place the topic within a global context, contextualise the } \\
\text { discussion and illuminate further some of the issues identified from the analysis } \\
\text { of the Scottish literature }\end{array}$ \\
\hline Currency & $\begin{array}{l}\text { The degree to which the literature represents current thinking and trends } \\
\text { For statistical data and reports, the most up-to-date data available } \\
\text { Preferably literature published within the past five years but not restricted to this } \\
\text { if a source is considered to be of value with regard to other criteria }\end{array}$ \\
\hline Availability & $\begin{array}{l}\text { Ease of access to the source } \\
\text { Preferably electronic }\end{array}$ \\
\hline
\end{tabular}


Table 1: The criteria guiding the selection of the literature

\section{Sourcing the literature}

This was achieved by initiating a series of Boolean searches using multiple operators on ERIC, such as 'poverty' and 'mental health'; 'socio-economic status' and 'attainment;' examining the last five years of publications in key international journals relevant to the field; following up sources in documentation, reports, the literature and the media; and accessing relevant websites.

\section{Thematic analysis}

Given the extensive nature of the data under scrutiny, thematic analysis was necessarily complex. This paper is not just concerned with establishing the relationships between poverty, attainment and mental health and wellbeing of children but with understanding the macrosystem within which the problem resides and the variables lying at the intersection which drive the relationships. Many of these variables are explored within the context of the paper and encompass things such as a child's sense of belonging to school. They are illustrated in Figure 2, a mapping of the key theme which is the principal focus of this paper.

\section{The Macrosystem}

\section{The International Context}

The poverty-related attainment gap is an internationally recognised problem (Gomendio, 2017; OECD, 2017d, 2018a; Parsons, 2016; Putnam, 2015). It resides within a culture of performativity (Ball, 2003; Solomon \& Lewin, 2016), deriving from social and economic drivers external to the school environment. It is sustained 
by neo-liberal economic forces and élitist structures (Parsons, 2016) which promote a culture of competitive individualism (B. S. Cooper \& Mulvey, 2015; Slee, 2018).

The equation of attainment to performance in standardised tests, which form the basis of international and national comparators, is widely critiqued within the literature (D'Agnese, 2018; Feniger \& Lefstein, 2014; Sellar \& Lingard, 2013). Slee (2018) argues that education systems, driven by neo-liberal ideology, create and perpetuate academic underachievement in disadvantaged groups, reinforcing privilege and exacerbating disadvantage (p.11).

Globalisation, channelled through a neo-liberal agenda of marketisation, competition and the commodification of public services, has had a profound impact on educational policy, leading to a convergence in educational policy-making 


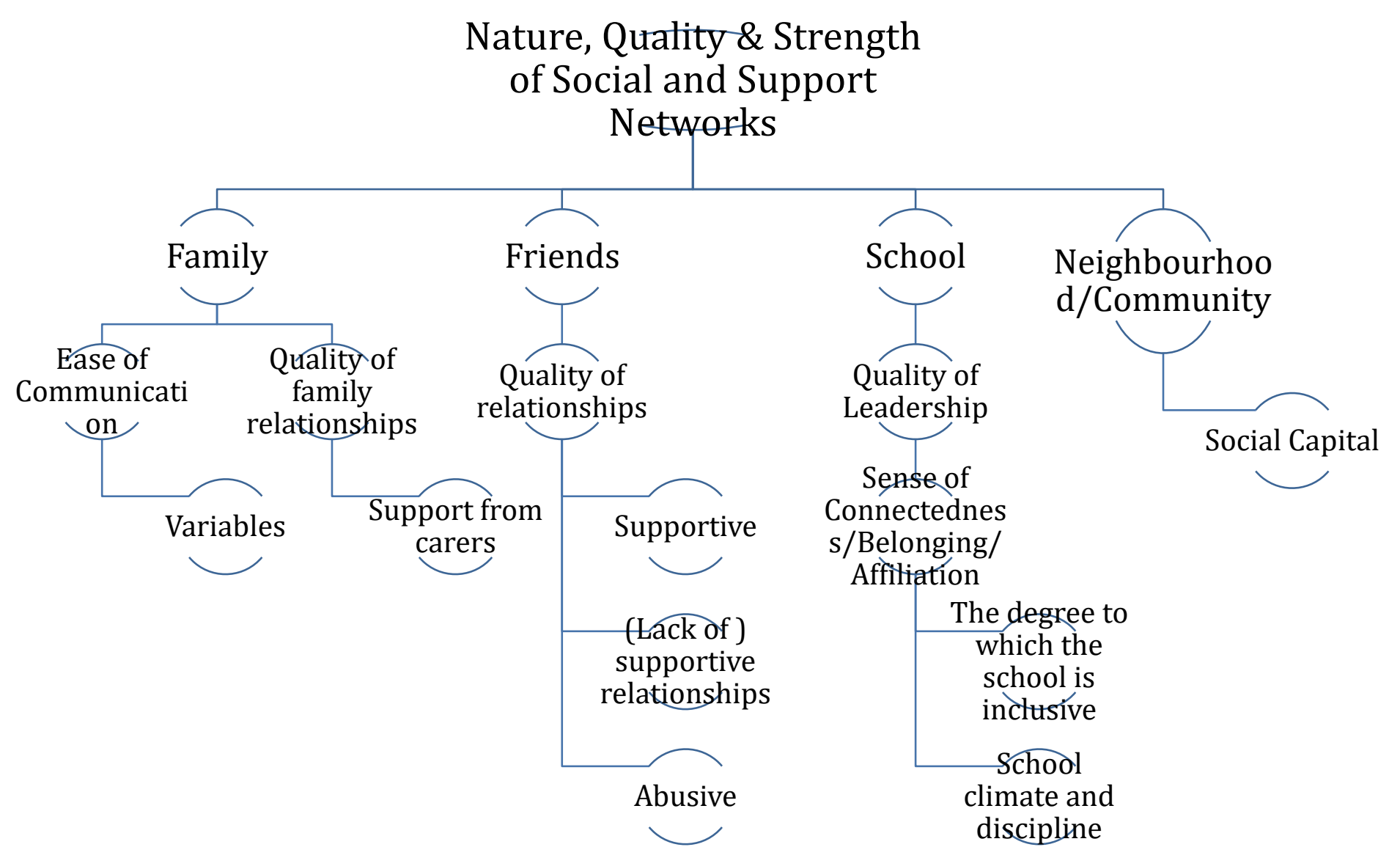

Figure 2: Mapping of 'The Nature, Quality \& Strength of Social and Support Networks' 
worldwide (D'Agnese, 2018; Sellar \& Lingard, 2018). Analysis of

documentation from the OECD and other international influencers (such as the McKinsey Foundation and the World Bank) reveals key themes which drive educational policy internationally (cc. Table 2 ).

\begin{tabular}{|l|l|l|}
\hline A drive for Social & A drive for Excellence & $\begin{array}{l}\text { A drive for Economic } \\
\text { Prosperity }\end{array}$ \\
\hline $\begin{array}{l}\text { Inclusion \& Diversity } \\
\text { Equity } \\
\text { Human Rights } \\
\text { Social Mobility } \\
\text { Wellbeing }\end{array}$ & $\begin{array}{l}\text { Curricular Reform and } \\
\text { Pedagogy } \\
\text { Teacher Professionalism } \\
\text { High Quality Leadership } \\
\text { Standards-agenda }\end{array}$ & $\begin{array}{l}\text { The impact of globalisation } \\
\text { and neo-liberal ideology } \\
\text { Building the workforce } \\
\text { Active \& responsible } \\
\text { citizens who contribute to } \\
\text { economic prosperity } \\
\text { Digital technologies }\end{array}$ \\
\hline \multicolumn{2}{|c|}{ Sustainability \& Empowerment } \\
\hline
\end{tabular}

Table 2: The key drivers of international educational policy

\section{The Scottish Policy Context}

The above can be clearly evidenced in Scottish educational policy. It is represented in the rhetoric of the National Improvement Framework with its emphasis on robust, evidence-based approaches, and the drive towards data-driven policy and practice which characterises the Scottish Attainment Challenge. This rhetoric is taken as unquestionable: there is no recognition of alternative, more organic routes to school improvement.

The Scottish Attainment Challenge The Scottish Government, drawing on insights gained from the London/City/National Challenge (Ainscow, 2015; Kidson \& Norris, 2014), has sought to address the poverty-related attainment gap through the Scottish Attainment Challenge. The London Challenge is not without its critics 
(Burgess, 2014; Greaves, Macmillan, \& Sibieta, 2014) with commentators forwarding alternative explanations for its apparent success (Mowat, 2018a). The Scottish Government has directed significant funding (£12.25 million in the current year) towards local authorities and schools through a range of different funding streams ${ }^{\text {iii }}$ and has put in place the National Improvement Framework, supported by the National Improvement Hub, to guide practice ${ }^{\mathrm{iv}}$.

Eradicating child poverty in Scotland The Scottish Attainment Challenge is located within a larger drive to eradicate child poverty in Scotland, reflected in legislation such as the 'Child Poverty Strategy' and the 'Child Poverty Act' (Scottish Government, 2014, 2017b), supported by an Action Plan (Scottish Government, 2016a) and subsequent Delivery Plan (Scottish Government, 2018c). Articulating with UNICEF's goals for sustainability (UNICEF Office of Research, 2017), the aim is to have fewer than $10 \%$ of children living in relative poverty and fewer than $5 \%$ in absolute poverty by 2030 . Critics, however, express concerns that pressures on local authority budgets and UK welfare reform will act to counteract efforts to reduce childhood poverty (Boyd, 2019; Freeman, 2017).

Mental health policy and provision Mental health is defined by the World Health Organisation (2013) as 'a state of wellbeing in which the individual realises his or her own abilities, can cope with the normal stresses of life, can work productively and fruitfully, and is able to make a contribution to his or her community' (p.6, pt. 6). The Scottish Government's ten year strategy (2017-2027) to improve mental health in Scotland (Scottish Government, 2017c) identifies key areas for investment with regard to the welfare of children and adolescents. Amongst the recommendations are access to, and support for, emotional and mental health in school and evidence-based interventions to address behavioural and emotional issues 
(p.13). The report stresses the important role which education can play in creating an environment in which children can 'feel safe, secure, resilient, confident, supported, and ready to learn' and the importance of working across professional boundaries to support children and families (ibid.).

Child and Adolescent Mental Health Services (CAMHS) provides treatment principally through outpatient and community services to children and young people with a wide range of mental health conditions ${ }^{\mathrm{V}}$ including Attention Deficit Hyperactivity Disorder (ADHD), anxiety, behaviour problems, depression and early onset psychosis. In 2017, 33,309 referrals were made to CAMHS of which 7,266 were rejected (around $1 / 5^{\text {th }}$ ). In the year ending February 2018, across Scotland, 15,864 children and young people started their treatment (a slight reduction in comparison to the two previous years) (Scottish Government, 2018e).

However, a report commissioned by the Scottish Parliament identifies a litany of problems. These range from a lack of access to specialist services; extensive waiting times for initial appointments and the commencement of treatment; to treatment in non-specialist settings, in adult wards and in geographical locations far from home (R. Murphy, 2016). For example, there were 77 admissions of 66 young people who were treated in non-specialist units in Scotland in 2016/17 (ibid.). To address these problems, the Scottish Government is injecting an additional $£ 250$ million to place counsellors in every secondary school, provide additional school nurses and invest in teacher education on the subject (The Scotsman 07/11/2018).

\section{The nature of poverty and how it manifests itself in Scotland}

Evidence from the National Health Service (NHS) Scotland illustrates the pervasive impact of poverty on children's lives. It explains the range of ways, both immediate and insidious, in which social and economic conditions impact on health and 
wellbeing, development, educational attainment and lifelong opportunities, acting as a critical risk factor with regard to the likelihood of children experiencing Adverse Childhood Experiences (NHS Scotland, 2018). Levels of poverty are correlated with relative income gaps: the greater the inequality in societies, the greater the level of poverty (Wilkinson \& Pickett, 2018; World Health Organisation, 2016). The ways in which poverty is defined and measured, however, is contested (McKinney, Hall, Lowden, McClung, \& Cameron, 2012): the main classifications are absolute, relative, persistent or severe (McKendrick, Mooney, Dickie, \& Kelly, 2011). The Joseph Rowntree Foundation (drawing on the work of Peter Townsend) defines relative poverty as: 'when someone's resources are so seriously below those commanded by the average individual or family that they are, in effect, excluded from ordinary living patterns, customs and activities' (https://www.jrf.org.uk/report/philosophical-reviewpoverty). The measure adopted is of someone living in a household with less than $60 \%$ of the median income (Wolff, Lamb, \& Zur-Szpiro, 2015).

Poverty levels in Scotland (19\% of the population in the period 2013-2016) are lower than those generally within the UK. Reductions in childhood poverty have been greater, and more sustained, than in the UK as a whole (Barnard, 2017). Poverty is also generational: those living in poverty are often trapped in a 'cycle of deprivation' with the majority of young people remaining in the same income quintile as their parents (McKinney et al., 2012).

Not all children living in poverty are living in areas of multiple deprivation, nor can it be assumed that all children living in areas of deprivation will be living in poverty (McKendrick, 2018). This finding brings into question the measure widely adopted by the Scottish Government to measure levels of poverty - the Scottish Index of Multiple Deprivation $^{\mathrm{vi}}$ (SIMD). Deprivation is a broader measure than poverty 
which takes account of multiple factors in people's lives, such as quality of housing. Poverty rates vary significantly according to geographical location. A third of children grow up in poverty in Glasgow in contrast to one tenth in Shetland (NHS Scotland, 2018). This will have major ramifications for service delivery in terms of 'closing the gap.' However, it is important to recognise that not all children living in poverty under-achieve, as is illustrated by Scottish Government statistics (Scottish Government, 2017a).

More than a quarter of children in Scotland were living in relative poverty (approximately 26,000 children) in the period 2015-2016 after account had been taken of housing costs, a rise of $4 \%$ on the previous year (Scottish Government, 2017d). $65 \%$ of Scottish children (aged 11-15) live in two-parent homes with $21 \%$ being brought up by single parents (Currie et al., 2015), 37\% of whom, according to Barnard (2017), live in poverty.

What is less easy to measure is the insidious nature of poverty and the cultures associated with it - how it eats into the psyche and impacts on the subjective wellbeing of families and children (Putnam, 2015). Within the media, portrayals and images of families living in poverty are invariably negative and the rhetoric is one of 'scroungers,' 'work shy,' 'teenage single mothers' and 'benefit cheats.' Yet, we know that, of those children living in relative poverty in Scotland, $66 \%$ live in working households (NHS Scotland, 2018). Treanor (2017) debunks the myth of 'poverty of aspiration,' establishing that families in poverty have aspirations for their children but they lack the cultural capital which would enable them to fulfil them. Scottish women play a key role in managing household income and in mitigating the effects of stigma associated with poverty for their children (Lister, 2004, 2010; McKinney, 2014). 


\section{Poverty and schooling in Scotland}

Schools can fulfil the function of a safe haven for children (Riley, 2017), building resilience (Henderson, 2013). However, they can also present as a barrier to children living in poverty both directly (for example, the cost of school trips) and indirectly (for example, the pressures and stressors of poverty which impede the capacity of the family to support school-relevant learning) (Glasgow Council, 2014). According to 1,000 young people surveyed by Children in Scotland vii , 'poverty $=$ lack of resources + lack of opportunity + limited resources at home' (2.2). At age three, children in poverty are nine months behind their peers in terms of school readiness (Glasgow Council, 2014). The Cost of the School Day report highlights a range of ways in which schools can 'poverty proof' themselves, such as raising staff awareness as to the impact of poverty on children's lives (ibid.). The annual report of the Children and Young Person's commissioner for Scotland (Children \& Young People's

Commissioner, 2017), states:

In Scotland, we still have almost one in four children affected by poverty. It is a shocking indictment of our tolerance to inequality in our society. As long as we have children living in poverty, Scotland's worthy ambitions in terms of early years development, educational achievement and life chances for our children will be thwarted. (p. 4)

\section{The nature of the attainment gap and how it manifests itself in Scotland}

While higher levels of attainment are more likely to be reported among pupils from more affluent families (World Health Organisation, 2016), attainment gaps are not restricted to poverty nor simply to Scotland. These issues play out, for example, in English schools in which, as Parsons (2016) shows, there is clear evidence of disparities in attainment with regard to gender, disability, race and ethnicity, with many children lying at the intersection. Correlational analysis consistently 
demonstrates that it is income poverty which is the deciding factor in determining low attainment (ibid.).

Scotland is within the band of countries in which the performance of children in the $10^{\text {th }}$ percentile in PISA tests at age 15 increased more than the median for all children. However, those in the lowest percentiles are least likely to reach national benchmarks (UNICEF Office of Research 2016). On a range of measures (as measured against the SIMD):

- attainment in the national curriculum (Curriculum for Excellence (CfE)) at key points from Primary 1 (P1) through to Secondary 3 (S3) (Scottish Government, 2018a)

- the now defunct Scottish survey of numeracy and literacy (P4, P7 \& S2) (Scottish Government, 2016c, 2017e); and

- $\quad$ erformance in national qualifications at SCQF levels 4-6 $6^{\text {viii }}$ undertaken in the senior phase of Scottish education (Scottish Government, 2019) the differentials in performance between those children in the upper quintiles of the SIMD in comparison to those in the lower are stark and widen at the highest levels of achievement (cc. chart 1). In the period 2016-2017 to 2017-2018, the gap in attainment between those in the highest and lowest SIMD quintile has increased for those attaining one pass or more at SCQF levels 4 and 5 but has decreased slightly at level 6 (Scottish Highers) but with a still significant percentage point gap of 37.4 at that level. 


\section{$\%$ of school leavers by total qualifications achieved at SCQF level 4 to 6 or better, by SIMD 2015-1018}

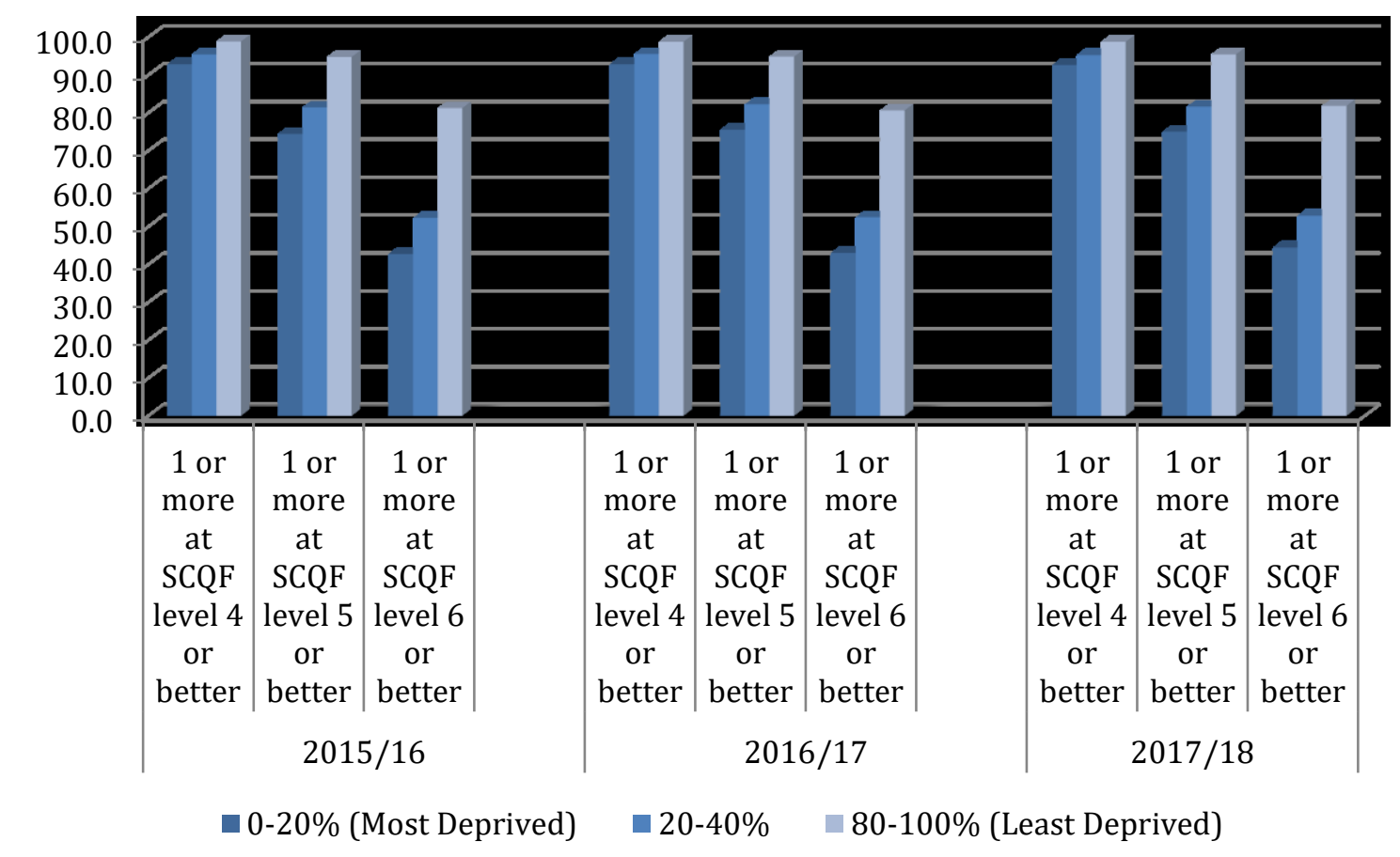

Chart 1: Attainment in National Qualifications according to SIMD levels over time (table A1. 1b) (Scottish Government, 2019)

This gap is reflected also in the proportion of Scottish school leavers entering Higher Education (HE): whereas $61.6 \%$ of those in the least deprived quintile entered $\mathrm{HE}$ in 2017-2018, only 25.7\% did so from the most deprived (Scottish Government, 2019), although the latter is increasing year on year (Scottish Government, 2018d).

Intersectionality There is a significant overlap between children living in SIMD decile 1 (most deprived), Looked After Children (LAC) and children recorded with Additional Support Needs (ASN) with 1,905 children lying at the intersection of all three ${ }^{\mathrm{ix}}$. Around $1 / 3^{\text {rd }}$ of children in SIMD decile one are recorded as having ASN and/or are Looked After (Scottish Government, 2016b).

The statistics for LAC and children recorded with ASN demonstrate similar patterns to those for children living in the lower SIMD deciles, but, for some 
categories, are even more extreme. For example, only $16 \%$ of children who are looked after for the full year, $8 \%$ of those looked after for part of the year (20162017) and $15 \%$ of children recorded with Social, Emotional and Behavioural Difficulties (2017-2018) gained a qualification at level 6 (Scottish Government, $2018 \mathrm{~b}, 2019)$. These statistics highlight the severity of the problem and the need for a nuanced and targeted approach in addressing the poverty-related gap in attainment.

\section{The nature, quality and strength of social and support networks}

The impact of poverty on health inequalities is mediated by risk and protective factors in children's lives associated with ease of communication within the family; networks of family and peer support; developing positive peer relationships and participating actively in networks; the school environment; and the neighbourhood environment and the degree to which it promotes or inhibits social capital (World Health Organisation, 2016). This theme (cc. figure 2) will therefore be explored through the eco-systems within which the child resides and interacts - the family, friends and peers, the school and community - drawing on ecological systems theory and ecological perspectives on resilience.

\section{Related to family}

Communication within the family The OECD (2017b) identifies that everyday family interactions can create the structure, regularity and support needed for children to become independent and to thrive. Communication within the family is an indicator of social support and connectedness, facilitating self-disclosure (World Health Organisation, 2016) and making it less likely that children will be the victims of bullying (OECD, 2017b). In particular, supportive communications between mothers 
and adolescents are particularly important for life satisfaction and reducing risktaking behaviours (World Health Organisation, 2016).

Scottish children find it easier to speak to their mothers about things that matter to them. Boys find it easier to speak to their parents than do girls but this declines with age for both genders, with the decline being more marked for girls in relation to their fathers.

\section{Family support}

It is recognised that parent-child relationships are central to children's development (Bronfenbrenner, 1986). Putnam (2015), in his treatise on the demise of the 'American Dream,' paints a picture of an America where family ties and the support from families for children growing up in poverty are diminishing. This, according to Putnam, takes place within a backdrop of globalisation, technological change, deunionisation, changing social norms and neo-liberal public policy (amongst other things), manifesting itself in a reduction of social and cultural capital and social mobility.

The Growing up in Scotland (GUS) survey establishes the importance of both supportive mother-child and father-child relationships for the socio-emotional wellbeing of 10 year-old children. As children grow older, perceptions of family support decline with around $50 \%$ of adolescents identifying with this at age 15 (Currie et al., 2015). Recognising the changing role of fathers, research has recently focused on positive engagement of fathers in their children's lives (Parkes, Riddell, Wight, \& Buston, 2017). The quality of father-child relationships is strongly correlated with that of mother-child relationships. The majority of children (84\%) enjoy 'good' or 'excellent' relationships with their fathers but twice as many children within the study are likely to report poorer relationships with their fathers than their mothers $(16 \% / 8 \%$ 
respectively). Amongst those factors which put children at risk of poorer father relationships are adverse home circumstances or family events, the father being the non-biological parent, poverty, remote location and gender (Parkes et al., 2017). The quality of father-child relationships is independently associated with wellbeing measures such as enjoyment of school, relationships with teachers and peers, emotional and behavioural problems and life satisfaction (ibid.).

Dysfunctional parenting, which impacts upon children's ability to form friendships, enjoyment of school and life satisfaction and arises from early maternal distress, is predictive of Scottish children's subjective wellbeing at age 7, as is family poverty and geographical location (Parkes, Sweeting, \& Wight, 2016). Treanor (2016), drawing from a longitudinal study relating to 5217 children born in 20042005 in Scotland, establishes that, for the younger children within the study, it is not comparisons with peers which impact upon the child's sense of wellbeing but the effects of high emotional maternal distress. This arises from feelings of financial vulnerability - a measure taking account of money worries, household debt and ability to manage finances, a more salient measure than objective income. The effect on children is malleable which implies that acting on maternal distress may potentially impact upon the subjective wellbeing of young children.

\section{Related to peers}

Networks of peer support Having strong networks of peer support has been identified as being one of the protective factors in children's lives, associated with higher levels of life satisfaction. This is particularly to the fore in adolescence where friendships tend to be more intimate, exclusive and constant and in which a lack of friends can lead to depression (OECD, 2017c). Strong networks of peer support (more prevalent in children from high affluence families) are associated with a wide range of 
positive indicators such as psychological wellbeing, self-esteem, achievement of academic goals, social adjustment to school and school relatedness (World Health Organisation, 2016). Putnam (2015) identifies that, in the USA, 'whom you go to school with matters' (p.165-166). The peer environment amplifies either the advantage or disadvantage that individual pupils bring to school, impacting across the whole school community.

For Scottish school children, perceptions of helpfulness of peers decrease with age (Currie et al., 2015). At age 11, around 3/4s of Scottish children found their classmates helpful and supportive but this declines as children get older. Older children feel less included with girls feeling more excluded than boys. Only $11 \%$ of girls at age 15 identified with 'not being left out' (Currie et al., 2015).

Social Media Social media has become a central component in the lives of adolescents and how they communicate with each other, playing an important role in learning, entertainment and socialisation (World Health Organisation, 2016). It has been found to act as a stimulus for social relationships and a positive correlation has been established with friendship quality and social capital (Gottschalk, 2019). Media use, particularly at night, has been related to poor sleep quality in children and adolescents (with very small relationships between it and anxiety and depression). Despite the media hype around addiction to social media and concerns about excessive use by children and young people, the literature is sparse and the impact of social media inconclusive (ibid.). There are age, socio-economic and gender patterns of usage, with more prevalence in older adolescents and girls aged $13 \& 15$ and in children from more affluent backgrounds (World Health Organisation, 2016). 
The prevalence of social media usage is higher in Scotland ${ }^{\mathrm{x}}$ at all three stages (age 11, 13 and 15) measured within the WHO survey than the average across the 44 countries.

Bullying behaviours In order for children and young people to have a sense of connectedness and belonging to school, a key aspect is feeling secure, safe and valued. Being bullied (or bullying) are known risk factors which impact upon children's subjective health and life satisfaction (OECD, 2017c; UNICEF Office of Research, 2016; World Health Organisation, 2016). There are clear patterns associated with age, gender and socio-economic status (the last in evidence in some, but not all, countries) with children living in more affluent homes being less likely to be bullied (World Health Organisation, 2016). Bullying is less prevalent where there is a strong disciplinary climate and teachers are perceived (by pupils) to behave fairly (OECD, 2017a; World Health Organisation, 2016).

In Scotland, bullying had had a significant impact on mental health and wellbeing, with an increase in suicidal behaviour and self-harm (Bainbridge, Ross, \& Woodhouse, 2017). Scottish children, aged 11, are at greater risk of being bullied than children in other nations and this is also the case for girls at age 13. However, at age 15 , fewer children are identifying with being bullied and the proportion is more in line with the average across all nations ( $8 \%$ for girls and 9\% for boys) (World Health Organisation, 2016). Fewer Scottish children identify themselves as being perpetrators of bullying than in other nations but the proportion rises for boys aged 15 $(8 \%)$.

The correlation between bullying and socio-economic status identified internationally also pertains to Scotland: Scottish children of low (bottom quintile) in comparison to high (top quintile) affluence groups are more likely to be bullied and 
boys, in particular, of low affluence are more likely to be perpetrators (World Health Organisation, 2016, p.198).

Prejudice-based bullying has increasingly come to the fore in Scottish education. The degree to which attention is devoted to prejudice-based bullying and responses to it within local authorities and schools is highly variable. School prevention and awareness programmes are more likely to cover bullying than prejudice (Dennell \& Logan, 2017).

Cyber bullying is a central aspect of bullying for Scottish children. Its impact has also contributed to sexual bullying with images being shared online (Bainbridge et al., 2017). There are clear gender patterns- its prevalence is significantly higher for girls at age 13 than for other nations ( $9 \%$ compared to $4 \%$ ) - but no significant association has been identified between affluence and cyber-bullying in Scottish children (World Health Organisation, 2016).

\section{Related to schooling}

A Sense of Belonging and Connectedness to School The degree to which children and adolescents have a sense of belonging or connectedness to school ${ }^{\mathrm{xi}}$ is associated with a wide range of positive indicators related to academic, psychological, behavioural and social outcomes (Prince \& Hadwin, 2013; Riley, 2017; World Health Organisation, 2016). Underpinning a sense of belonging is a caring and supportive school ethos and the promotion of trusting, respectful and affirmative relationships within the school community (Tobbell \& O'Donnell, 2013). For Riley (2017), a sense of belonging is about accepting children for who they are and children having a sense of agency and voice:

Teachers and young people flourish in schools which foster their creativity, resilience and sense of agency when schools become places in which what you think, what you say and what you do make a difference. When young people are seen and have a voice, their skills and confidence grow and they flourish (p.113). 
This, in turn, is dependent on the quality of school leadership in setting the tone and vision for the school (a prominent theme in OECD documentation (Schleicher, 2014)); the quality and nature of partnerships; and engagement with parents.

Effective engagement with parents can be particularly challenging for schools located in areas of multiple deprivation as it has been established that parental engagement increases with social status, income and levels of parental education (Harris \& Goodall, 2008; Putnam, 2015). Such engagement needs to focus on providing guidance and support to parents so that they can support the learning of their child at school and to affirming the role of parents in this respect - parents 'need to know that they matter' (p. 286).

Disadvantaged students are less likely to have a sense of belonging to the school community (OECD, 2017a). For some young people on the periphery of school life their learning experience is often fragmented, inconsistent and interrupted (Riley, 2017): 'They held on to school life by a perilously thin thread' (p. 36). In some school communities a 'them and us' culture prevails, characterised by fractured relationships between teachers and pupils and between the school and families. A lack of trust lies at the root of the problem: 'Two alien tribes inhabited the divided world of school, each speaking its own language' (p.36). This can only have the effect of disenfranchising young people from school life with long-term consequences for their learning and achievement.

Attention has already been drawn to the ways in which schools can act as a barrier to participation for children and young people living in poverty (Glasgow Council, 2014). In Scotland, The 'Cost of the School Day Toolkit' (Child Poverty Action Group, 2018) (designed by the Child Poverty Action Group (CPAG)) supports 
schools in examining their policies and practice in order to remove the barriers to participation for children living in poverty. Liking of school acts as a protective factor against health compromising behaviours and a lack of connection to school is related to a series of negative health indicators, such as psychosomatic symptoms. Unfortunately, liking of school decreases for Scottish children as they get older but the trend is more marked for girls: only a quarter of girls who identified with 'liking school a lot' at age 11 did so at age 15 (Currie et al., 2015).

Teacher Support These age-related and gender patterns are replicated also with regard to perceptions of support from teachers. Negative relationships with teachers have a major impact on children's sense of belonging to school and general sense of wellbeing (OECD, 2017c): 'Students in "happy” schools (schools where students' life satisfaction is above the average in the country) reported much greater support from their teachers than did students in "unhappy" schools.' (p.7). Positive relationships between children and teachers promote a range of positive health indicators, indicating that schools can act as protective factors in children's lives (World Health Organisation, 2016). Teacher connectedness is an important aspect of children's subjective wellbeing, irrespective of demographics and independent of students' perceptions of their academic performance, ameliorating depressive symptoms and increasing self-esteem in adolescents (García-Moya et al., 2015). In contrast, poor relationships with teachers has a major (negative) impact on children's sense of belonging to school and general sense of wellbeing (OECD, 2017c).

In a small-scale, principally qualitative, study in a Scottish secondary school, children with SEBD had much more negative perceptions of their relationships with their teachers than their relatively well-behaved peers (pupils who had not been referred to senior management for indiscipline). The differentials in pupil response 
between the two groups were of high statistical significance. These perceptions related to the degree to which they perceived that they got on well with their teachers, could talk to them and respected them; and the degree to which they considered that their teachers liked, respected, cared for them and treated them fairly (Mowat, $2010)^{\mathrm{xii}}$.

\section{The wider community}

The final aspect relates to the nature and strength of the networks within the community with which the child engages and the degree to which the community promotes social capital, both of which act to mediate the impact of poverty on health inequalities in children and young people (World Health Organisation, 2016). Putnam (2015) identifies the loss of community as being a key aspect in the decline of social mobility in the USA. In the post- ( $2^{\text {nd }}$ world $)$ war years, adults within the community took a collective responsibility towards children across all social classes - seeing them as 'our kids.' They actively created opportunities for them (a form of linking social capital) - "One of the ministers in the town was keeping an eye on me," he says, "and mentioned my name to the university where I ended up" (p.3). However, with the decline in the manufacturing industry, the diaspora of communities, a weakening of family ties and a rise in child poverty (amongst other factors), community ties, over time, weakened. Riley (2017) argues that how schools understand and connect to their communities and neighbourhoods - and view their cultures, practices and beliefs - will shape young people's sense of self and identity.

One of the impacts of poverty is the limitations which it places on children and young people's capacity to participate in the wider community (Glasgow Council, 2014). Most activities which have a cost attached to them are unaffordable to children living in poverty and transport costs can be prohibitive (ibid.). 
Deuchar (2009), drawing on an ethnographic study of Glasgow gangs, argues that young people who fail to form strong social networks within the school environment will seek to do so in other ways, such as affiliation with gangs. Whilst such affiliation may foster social capital to a degree (for example, bonding among peers), it does not foster the positive networks which may assist young people in rising from poverty and may lead them down the path of criminalisation. It also has the effect of restricting movement within and beyond communities due to territorial boundaries, limiting opportunities for participation and advancement (ibid.).

\section{Some Initial Reflections}

In examining the relationships and intersection between poverty, attainment and mental health and wellbeing in children and young people what has emerged is complexity. There are few studies which establish a direct relationship between poverty, attainment and children's mental health and wellbeing. Many, however, establish indirect links, such as the degree to which the child has a sense of belonging or connectedness to school, the variables which make this more or less likely in the first instance and how this then relates to the child's sense of wellbeing, achievement motivation and, ultimately, attainment.

Examination of the literature has revealed an extensive range of variables which act as protective or risk factors in the lives of children and young people living in poverty, fostering or impeding their attainment and/or mental health and wellbeing. This relationship is by-directional or cyclical in nature. While childhood poverty may potentially impede the attainment and mental health and wellbeing of children (dependent on the interaction of risk and protective factors at the individual, social, societal and political levels (Mowat, 2015)), the impact of this for some children may subsequently impede their capacity as adults to lead healthy lives and make a 
prosperous living (to rise above poverty), leading to inter-generational poverty. Many variables (for example, relationships between teachers and pupils) can act either as facilitators or barriers and may lie on a continuum - it is a matter of degree.

Bronfenbrenner's bio-ecological systems theory has enabled an holistic understanding of the problem which does not individualise it nor create a blame culture of 'problem families,' 'inadequate parents,' 'difficult, troubled children' or 'failing schools' - the last of these a rhetoric common south of the border. We have come to understand children's lives as nested within societal norms, public policy and within the interlocking networks which make up the ecosystem. The paper has highlighted the importance of social support and networks around communities, families and children, built on respectful relationships, trust and reciprocity, all important aspects of social capital. This is exemplified in the strength of peer bonds (bonding capital); the quality of teacher-pupil relationships and sense of belonging and connectedness to school (bridging capital); and the degree to which the community and the networks within which the child participates foster bridging and linking capital. Social capital is also represented within the networks of the immediate and extended family. However, it has also been established that children living in poverty have less access to these forms of capital in ways that will enhance their lives.

\section{Discussion \& Conclusions}

There are tentative indications that there is some progress in closing the povertyrelated attainment gap in Scotland but trends are not clear and the scale of the problem is significant. On a more positive note, almost nine out of ten headteachers (of 500 surveyed) had seen improvements in attainment or wellbeing (Education Scotland News Digest 31/05/2019). 
As previously intimated, the approach adopted by the Scottish Government has been informed by the London/City/National Challenge (see Mowat, 2018a) but what makes the Scottish approach distinctive? The key aspects are cultural and political. Social justice lies at the heart of Scotland as a nation - it is emblazoned on the Scottish maze. Politically, Scotland leans less towards individualist cultures associated with neo-liberalism (although, as previously identified, this is becoming more characteristic) and more towards collective, socialist, and liberal cultures, reflected in the comprehensive system of schooling (D. Murphy, Croxford, Howieson, \& Raffe, 2015). As a smaller nation, the political élite is smaller and there are more opportunities for dialogue across different constituencies, professions and disciplines. There is a more consensual approach towards educational policy in Scotland and the strife which characterises education south of the border is less in evidence (Mowat \& McMahon, 2018). There is a more positive rhetoric towards the teaching profession and the professionalism of teachers is recognised (Swinney, 2019). However, given the distinctiveness of the Scottish context, how appropriate is it import policy from south of the border unquestioningly? Steiner-Khamsi (2014) (cited in Mowat, 2018a) argues that policy borrowing is not the rational process that people imagine it to be. It has been identified that the greater the synchronicity between the characteristics of the two education systems involved in the process, the greater the likelihood of success (Halpin and Troyna, 1995, cited in Mowat 2018a). As such, cultural and political differences, reflected within the distinctive policy, systems and structures between the two nations of England and Scotland, may potentially act to impede the translation of policy into practice. 
Policy and cultural values A key message for the policy community is that this problem cannot be understood or addressed through educational policy and practice alone. It is highly complex and requires an inter-disciplinary lens and perspective to be brought to bear on it. The implication of this is the need to invest in high quality inter-disciplinary research drawing on both quantitative and qualitative approaches. An over-reliance on statistical data only tells us part of the story and, in the view of the author, can potentially skew the efforts of schools to address the problem through an over-reliance on approaches which can be easily quantified rather than those which are of greatest value in fostering children's learning and wellbeing.

There is a need to develop a deeper understanding of the drivers of educational policy at an international level and how they impact on local solutions, in the process, challenging neo-liberal orthodoxies which position education primarily as a commodity and as a means of attaining economic prosperity rather than as a social good in its own right. Sellar and Lingard (2013) identify that, internationally, the cultural and social context of educational reform is often underplayed. This, according to the authors, is particularly relevant with regard to the impact of structural inequality on educational outcomes which they observe is often missing in the explanations provided by the OECD for poor quality and equity outcomes in PISA (p. 723). It has been argued (MacBeath et al., 2007) that the normal assumptions as to what constitutes 'good practice' and prescriptions for school improvement need to be put to the side when considering the needs of schools serving families and communities which have been 'cut adrift' from society. There is therefore a need to examine and interrogate the values which underpin policy and the cultural influences on society which lead to policy formation and to give consideration to the specific set 
of circumstances which may pertain in schools located in areas of multiple deprivation.

The quest to 'close the gap' requires a political solution which has an holistic focus on all aspects of public policy which have a bearing on the problem, requiring investment in public services, including early years provision. Given the fractured political arena within the context of BREXIT in the United Kingdom, there is an imperative to reach consensus across political parties to ensure that investment is long-term and sustainable beyond the term of a single government.

The challenges facing policy makers (and those invested with putting policy into practice) are firstly, the creation of more just, tolerant societies where the distribution of family income is more evenly spread across social strata, challenging neo-liberal orthodoxies and the policies emanating from them. Secondly, a deeper examination of how economic, social, health and educational policy interact with each other in the lives of children and families living in poverty such that resources and support can be channelled in more efficient and effective ways, addressing the inequities in educational outcomes and the mental health and wellbeing of children. Reframing the narrative We need to reframe the narrative around childhood poverty, attainment and mental health and wellbeing, moving it away from deficit understandings of communities, families and children (even if well meant). The problem needs to be understood within the broader framework of inequalities in society and framed in ecological terms. It should not be individualised (the solution being seen as 'making children more resilient').

Nature, strength and quality of social and support networks As previously intimated, this paper has highlighted an extensive range of variables associated with living in poverty which either act directly or indirectly on the quality of family life 
impacting, in turn, on the mental health and wellbeing of children and young people, such as the effect of maternal financial vulnerability creating stressors within the home. It is therefore crucial to build an infra-structure around communities, families and schools to alleviate the stressors associated with living in poverty (for example, support for parenting and mothers in particular; access to high quality early years provision, home-link workers, educational psychologists, counsellors and mental health services). The challenge therefore is to ascertain how networks of support can be built around communities and families such that social capital can be furthered and resources directed towards this end. This implies a high degree of collaboration between different stakeholder groups, creating the spaces and opportunities for interprofessional, inter-sectoral and inter-agency work to take place and for shared understandings of the problem to develop. It also implies adopting an holistic approach in working with families, building on the strengths of the community and listening respectfully to their voices.

Likewise, this paper has also highlighted the importance of good communication and relationships within the family, within the school environment and between the home and school and, crucially, the need for children to have a sense of connectedness and belonging to school. As highlighted by the previously outlined statistics showing that, as children progress through the school system, their perceptions on a range of measures (for example, support from teachers) become more negative, this is a particular challenge for secondary schools. Building a sense of community in schools is a key aspect of building strong social and support networks (Khon, 2001; Sergiovanni, 1994) but it also about the strength of networks between schools and their wider communities (Price, 2008). 
A key challenge therefore is to examine the degree to which schools are inclusive in their policies, practice and ethos and may (sometimes inadvertently) disenfranchise children and families living in poverty and to examine the role which leadership (at all levels of the system) plays in this. This extends to the fostering of positive, nurturing and supportive relationships across the school community (P. Cooper, 2008) and meaningful engagement with families living in poverty (Buchanan \& Buchanan, 2017; Harris \& Goodall, 2008).

Implications for the Research Community There are significant gaps in the literature, particularly relating to the mental health and wellbeing of children. For example, there was a thirteen year gap in the conduct of the 'Mental Health of Children and Young People in England' survey. There is a need both within England and Scotland for the collection of data on a regular basis focussing specifically on the mental health and wellbeing of children and adolescents from both a quantitative and qualitative perspective other than that which is a by-product of more generalised longitudinal studies, such as Growing up in Scotland.

A key area for further exploration is to examine through empirical study, from the perspective of children living in poverty and related stakeholders, a sense of belonging to school - what this means to them, what acts to facilitate it or acts as a barrier, what needs to happen at a political, societal and local level to make it a reality and why it is important. This includes an examination of the efficacy of approaches to eliminate bullying behaviours and prejudice-based bullying in schools. A further fruitful avenue of exploration would be to explore empirically the key elements of building networks of support around communities, families and schools through an examination of potential facilitators and barriers, drawing out the implications for public and fiscal policy. 


\section{Acknowledgements}

I would like to thank Emeritus Professor John MacBeath for acting as a critical friend in the preparation of this paper.

Coda

This work has been taken forward through a Scottish Universities Insight Institute Seminar series led by the Universities of Strathclyde and Edinburgh. The organising team constituted four Scottish universities, two local authorities and five $3^{\text {rd }}$ sector organisations. We worked with children in two local authorities to explore what a sense of belonging meant to them. The seminar series, hosted over four days, was attended by representatives of the Scottish Government and the policy community, representation from sixteen professions (including education and the health service) and academics from sixteen academic disciplines. Video/audio recordings and powerpoint presentations are available on the SUII website, including the work with children relating to a sense of belonging. Sets of research briefs and key recommendations have been produced and are available at https://www.scottishinsight.ac.uk/Programmes/OpenCall201819/PEAW.aspx.

\section{References}

Ainscow, M. (2015). Towards Self-Improving School Systems: Lessons From A City Challenge. London: Routledge.

Bainbridge, J., Ross, C., \& Woodhouse, A. (2017). Inquiry into Bullying and Harassment in Schools: Children's and Young People's Voices and Experiences of Bullying and Harrasment in Schools. Edinburgh: Children in Scotland (in conjunction with the Equalities and Human Rights Commission and the Scottish Parliament).

Ball, S. J. (2003). The Teacher's Soul and the Terrors of Performativity. Journal of Education Policy, 18(2), 215-228.

Barnard, H. (2017). Poverty in Scotland 2017. York: Joseph Rowntree Foundation.

Boyd, I. (2019, May 31). Tackling the Pupil Equity Paradox. Times Educational Supplement Scotland, pp. 20-23.

Brewin, M., \& Statham, J. (2011). Supporting the Transition from Primary School to Secondary School for Children who are Looked After. Educational Psychology in Practice: theory, research and practice in educational psychology, 27(4), 365-381.

Bronfenbrenner, U. (1986). Ecology of the Family as a Context for Human Development: Research Perspectives. Developmental Psychology, 22(6), 723733.

Bronfenbrenner, U., \& Morris, P. A. (2006). The Bioecological Model of Human Development. In R. M. Lerner (Ed.), Handbook of Child Psychology: Theoretical Models of Human Development (6th ed., Vol. 1, pp. 793-828). New Jersey: Wiley.

Buchanan, K., \& Buchanan, T. (2017). Relationships with Families: Have Educators overlooked a Critical Piece of the Puzzle? Improving Schools, 20(3), 236 246.

Burgess, S. (2014). Understanding the Success of London's schools (Vol. Working Paper No. 14/333). Bristol: Centre for Market and Public Organisation.

Child Poverty Action Group. (2018). Cost of the School Day Toolkit: Edinburgh: Child Poverty Action Group.

Children \& Young People's Commissioner. (2017). Annual Report of the Children \& Young People's Commissioner. Edinburgh: CYPCS. 
Cooper, B. S., \& Mulvey, J. D. (2015). Connecting Education, Welfare, and Health for American Families. Peabody Journal of Education, 90(5), 659-676.

Cooper, P. (2008). Nurturing Attachment in School: Contemporary Perspectives on Social, Emotional and Behavioural Difficulties. Pastoral Care in Education, 26(1), 13-22.

Currie, C., Whitehead, R., Van der Sluijs, W., Currie, D., Rhodes, G., Neville, F., \& Inchley, J. (2015). Health Behaviour in School-aged Children: World Health Organization Collaborative Cross-National Study (HBSC): findings from the 2014 HBSC survey in Scotland. St Andrews: University of St Andrews: Child and Adolescent Health Research Unit (CAHRU).

D'Agnese, V. (2018). Reclaiming Education in the Age of PISA: Challenging OECD's Educational Order. London: Routledge.

Dennell, B. L. L., \& Logan, C. (2017). Prejudice-based bullying in Scottish schools: A Research Report. Edinburgh: LGBT Youth Scotland and RespectMe.

Deuchar, R. (2009). Gangs, Marginalised Youth and Social Capital. Edinburgh: Dunedin Press.

Feniger, Y., \& Lefstein, A. (2014). How not to Reason with PISA Data: An Ironic Investigation. Journal of Education Policy, 29(6), 845-855.

Freeman, T. (2017, February 10). Child Poverty Bill published by Scottish Government, News item. Holyrood. Retrieved from file://Users/jis04102/Desktop/Poverty\%20paper/Scottish\%20Government\%2 0Policies\%20\&\%20Statistics/Child\%20Poverty\%20Bill.webarchive

García-Moya, I., Brooks, F., Morgan, A., \& Moreno, C. (2015). Subjective WellBeing in Adolescence and Teacher Connectedness: A Health Asset Analysis. Health Education Journal, 74(6), 641-654.

Garmezy, N. (1971). Vulnerability research and the Issue of Primary Prevention. American Journal of Orthopsychaitry, 41(1), 101-116.

Glasgow Council. (2014). Cost of the School Day Seminar Report. Edinburgh: Child Poverty Action Group.

Gomendio, M. (2017). Empowering and Enabling Teachers to Improve Equity and Outcomes for All. International Summit on the Teaching Profession. Paris: OECD. http://www.oecd.org/education/empowering-and-enabling-teachers-toimprove-equity-and-outcomes-for-all-9789264273238-en.htm

Gottschalk, F. (2019). Impacts Of Technology Use on Children: Exploring Literature on The Brain, Cognition and Well-Being. OECD Working Paper (Vol. 195). Paris: OECD. Retrieved from https://www.oecdilibrary.org/education/impacts-of-technology-use-on-children_8296464e-en

Greaves, E., Macmillan, L., \& Sibieta, L. (2014). Lessons from London Schools for Attainment Gaps and Social Mobility. London: Social Mobility and Poverty Commission. Retrieved from https://www.ifs.org.uk/publications/7243

Halpin, D., \& Troyna, B. (1995). The Politics of Education Policy Borrowing. Comparative Education, 31(3), 303-310.

Harris, A., \& Goodall, J. (2008). Do parents know they Matter? Engaging all Parents in Learning. Educational Research and Reviews, 50(3), 277-289.

Henderson, N. (2013). Havens of Resilience. Educational Leadership, 71(1), 22-27.

Jesson, J., Matheson, L., \& Lacey, F., M. (2011). Doing your Literature Review: Traditional and Systematic Techniques. London: SAGE publications.

Khon, A. (2001). Beyond Discipline: From Compliance to Community. New Jersey, USA: Merrill Education. Association of Supervision and Curriculum Development. 
Kidson, M., \& Norris, E. (2014). Implementing the London Challenge. London: Institute for Government (supported by Joseph Rowntree Foundation).

Lister, R. (2004). Poverty. Cambridge, UK: Polity.

Lister, R. (2010). Linking Women's and Children's Poverty. In S. Chant (Ed.), The International Handbook of Gender and Poverty (pp. 167-172). Northampton, MA: Edward Elgar.

MacBeath, J., Gray, J. M., Cullen, J., Frost, D., Steward, S., \& Swaffield, S. (2007). Schools on the Edge: Responding to Challenging Circumstances. London: Chapman Publications.

McGonigal, J., Doherty, R., Mills, S., Mott, J., McDonald, A., Redford, M., . . . Allan, J. (2005). Social Capital Theory: A Review: AERS Schools and Social Capital Network. Retrieved from https://philpapers.org/rec/MCGSCS-3

McKendrick, J. (2018). Local Contributions to Tackling Poverty and Inequality in Scotland. Glasgow: Scottish Poverty and Inequality Research Unit.

McKendrick, J., Mooney, G., Dickie, J., \& Kelly, P. (Eds.). (2011). Poverty in Scotland 2011: Towards a More Equal Scotland? . Edinburgh: Child Poverty Action Group.

McKinney, S. (2014). The Relationship of Child Poverty to School Education. Improving Schools, 17(3), 203-216.

McKinney, S., Hall, S., Lowden, K., McClung, M., \& Cameron, L. (2012). The Relationship between Poverty and Deprivation, Educational Attainment and Positive School Leaver Destinations in Glasgow Secondary Schools. Scottish Educational Review, 44(1), 33-45.

McLure, I., Gilligan, R., \& Smith, M. (2015). The Pinkie Resilience Project: Enhancing Equality, Boosting Wellbeing and Realising Potential in Scottish Schools. Glasgow: Scottish Universities Insight Institute. Retrieved from https://www.scottishinsight.ac.uk/Default.aspx?tabid=8156

Mowat, J. G. (2010). "He comes to me to talk about things": Supporting Pupils Experiencing Social and Emotional Behavioural Difficulties - A Focus upon Interpersonal Relationships. Pastoral Care in Education, 28(3), 163-180.

Mowat, J. G. (2015). Towards a New Conceptualisation Of Marginalisaion. European Educational Research Journal, 14(5), 454-476.

Mowat, J. G. (2018a). Closing the Attainment Gap - A Realistic Proposition or an Elusive Pipe-Dream? Journal of Education Policy, 33(2), 299-321. doi: 10.1080/02680939.2017.1352033

Mowat, J. G. (2018b). 'Closing The Gap': Systems Leadership is no Leadership at all without a Moral Compass - A Scottish Perspective. School Leadership \& Management, 39(1), 48-75.

Mowat, J. G., \& McMahon, M. (2018). Interrogating the Concept of 'Leadership At All Levels': A Scottish Perspective. Professional Development in Education, 45(2), 173-189.

Murphy, D., Croxford, L., Howieson, C., \& Raffe, D. (Eds.). (2015). Everyone's Future: Lessons from Fifty Years of Scottish Comprehensive Schooling. London: Trentham.

Murphy, R. (2016). Child and Adolescent Mental Health - Trends and Key Issues SPICe Briefing. Edinburgh: University of Edinburgh.

Newman, B., M, \& Newman, P., R. (2016). Theories of Human Development (2nd ed.). London: Psychology Press. 
NHS Scotland. (2018). Child Poverty. Retrieved from

$\mathrm{http}: / / \mathrm{www} \cdot$ healthscotland.scot/health-inequalities/fundamentalcauses/poverty/child-poverty

OECD. (2017a). Are students happy? PISA 2015 Results: Students' Well-being. Vol 3. PISA in Focus (Vol. 71). Paris: OECD. Retrieved from https://www.oecdilibrary.org/education/are-students-happy_3512d7ae-en

OECD. (2017b). PISA 2015 Results (Volume III): Students' Well-Being. Paris: OECD. Retrieved from https://www.oecd.org/education/pisa-2015-resultsvolume-iii-9789264273856-en.htm

OECD. (2017c). PISA 2015 Results (Volume III): Students' Well-Being. Country Note: UK. Paris: OECD. Retrieved from https://www.oecd.org/pisa/PISA2015-students-well-being-UnitedKingdom.pdf

OECD. (2017d). Trends Shaping Education Spotlight 8: Mind the Gap: Inequity in Education Trends Shaping Education. Paris: OECD. Retrieved from http://www.oecd.org/education/ceri/Spotlight8-Inequality.pdf

OECD. (2018a). Equity in Education: Breaking Down Barriers to Social Mobility. Paris: OECD Publishing. Retrieved from https://www.oecd.org/publications/equity-in-education-9789264073234en.htm

OECD. (2018b). Trends Shaping Education Spotlight 14: Good Vibrations: Students' Well-being. Paris: OECD. Retrieved from https://www.oecd.org/education/ceri/Spotlight-14-Good-VibrationsStudents\%27-Well-being.pdf

Olsson, C., A., Bond, L., Burns, J., M., Vella-Brodrick, D., A., \& Sawyer, S., M. (2003). Adolescent Resilience: a Concept Analysis. Journal of Adolescence, 26, 1-11.

Parkes, A., Riddell, J., Wight, D., \& Buston, K. (2017). Growing up in Scotland: Father-child Relationships and Child Socio-Emotional Wellbeing. York: Joseph Rowntree Foundation.

Parkes, A., Sweeting, H., \& Wight, D. (2016). What Shapes 7-Year-Olds' Subjective Well-Being? Prospective Analysis of Early Childhood and Parenting using The Growing Up In Scotland Study. Social Psychiatry and Psychiatric Epidemiology, 51(10), 1417-1428.

Parsons, C. (2016). Ethnicity, Gender, Deprivation and Low Educational Attainment in England: Political Arithmetic, Ideological Stances and the Deficient Society. Education, Citizenship and Social Justice, 11(2), 160-183.

Price, H. B. (2008). Mobilizing the Community to help Students Succeed. Alexandria, Virginia, USA: ASCD.

Prince, E. J., \& Hadwin, J. (2013). The Role of a Sense Of School Belonging in understanding the Effectiveness of Inclusion of Children with Special Educational Needs. International Journal of Inclusive Education, 17(3), 238262.

Putnam, R. D. (2015). Our Kids, the American Dream in Crisis (Reprint Edition ed.). New York: Simon and Schuster.

Riley, K. A. (2017). Place, Belonging and School Leadership : Researching to Make the Difference. London: Bloomsbury Academic.

Rogošić, S., \& Baranović , B. (2016). Social Capital and Educational Achievements: Coleman vs. Bourdieu. Center for Educational Policy Studies Journal,, 6(2), 81-100. 
Rutter, M. (2012). Resilience: Causal Pathways and Social Ecology. In M. Ungar (Ed.), The Social Ecology of Resilience: A Handbook of Theory and Practice (pp. 33-42). New York: Springer.

Schleicher, A. (2014). Equity, Excellence and Inclusiveness in Education: Policy Lessons from Around the World: Background Report for the 2014 International Summit of the Teaching Profession. Paris, France: OECD. Retrieved from https://www.oecd-ilibrary.org/education/equity-excellenceand-inclusiveness-in-education_9789264214033-en

Scottish Government. (2014). Child Poverty Strategy for Scotland: Our approach 2014-2017. Edinburgh: Scottish Government. Retrieved from https://www.gov.scot/publications/child-poverty-strategy-scotland-approach2014-2017/

Scottish Government. (2016a). Fairer Scotland Action Plan. Edinburgh: Scottish Government. Retrieved from http://www.gov.scot/FairerScotland.

Scottish Government. (2016b). School Education Statistics. Retrieved from http://www.gov.scot/Topics/Statistics/Browse/School-Education.

Scottish Government. (2016c). Scottish Survey of Literacy and Numeracy 2015: Numeracy. Edinburgh: Scottish Government. Retrieved from https://www.gov.scot/publications/scottish-survey-literacy-numeracy-2015numeracy/

Scottish Government. (2017a). Achievement of Curriculum for Excellence (CfE) Levels 2016/17. Edinburgh: Scottish Government. Retrieved from http://www.gov.scot/Publications/2017/12/5300

Child Poverty (Scotland) Act, 6 (2017b). Retrieved from http://www.legislation.gov.uk/asp/2017/6/enacted

Scottish Government. (2017c). Mental Health Strategy: 2017-2027. Edinburgh: Scottish Government. Retrieved from https://www.gov.scot/publications/mental-health-strategy-2017-2027/

Scottish Government. (2017d). Poverty and Income Inequality in Scotland: 2015/16: A National Statistics publication for Scotland. Edinburgh: Scottish Government. Retrieved from https://www.gov.scot/publications/povertyincome-inequality-scotland-2015-16/ http://www.gov.scot/Resource/0051/00515392.pdf.

Scottish Government. (2017e). Scottish Survey of Literacy and Numeracy 2016: Literacy. Edinburgh: Scottish Government. https://www.gov.scot/publications/scottish-survey-literacy-numeracy-2016literacy/

Scottish Government. (2018a). Achievement of Curriculum for Excellence levels (CfE) Levels 2017/2018. Edinburgh: Scottish Government. Retrieved from https://www.gov.scot/publications/achievement-curriculum-excellence-cfelevels-2017-18/

Scottish Government. (2018b). Education Outcomes for Looked After Children 2016/17. Edinburgh: Scottish Government. Retrieved from https://beta.gov.scot/publications/education-outcomes-scotlands-lookedchildren-2016-17/.

Scottish Government. (2018c). Every Child, Every Chance: The Tackling Child Poverty Delivery Plan 2018-2022. Edinburgh: Scottish Government. Retrieved from https://http://www.gov.scot/Resource/0053/00533606.pdf.

Scottish Government. (2018d). Initial Destinations of Senior Phase School Leavers, No. 2: 2018 Edition. Edinburgh: Scottish Government. Retrieved from 
https://www.gov.scot/publications/initial-destinations-senior-phase-schoolleavers-2-2018-edition/pages/0/

Scottish Government. (2018e). Rejected Referrals to Child and Adolescent Mental Health Services: Audit. Edinburgh: Scottish Government. Retrieved from https://www.gov.scot/publications/rejected-referrals-child-adolescent-mentalhealth-services-camhs-qualitative-quantitative/

Scottish Government. (2019). Summary Statistics for Attainment and Initial Leaver Destinations. (No. 1: 2019 Edition). Retrieved from https://www2.gov.scot/Topics/Statistics/Browse/SchoolEducation/Publications/Pub-SS-AIL

Sellar, S., \& Lingard, B. (2013). The OECD and General Governance in Education. Journal of Education Policy, 28(5), 710-725.

Sellar, S., \& Lingard, B. (2018). International Large-Scale Assessments, Affective Worlds And Policy Impacts In Education. International Journal of Qualitative Studies in Education, 31(5), 367-381.

Sergiovanni, T. J. (1994). Building community in schools. San Fransisco: Jossey-Bass.

Slee, R. (2018). Inclusive Education isn't dead, it just smells funny. London: Routledge.

Solomon, Y., \& Lewin, C. (2016). Measuring 'Progress': Performativity as both Driver and Constraint in School Innovation. Journal of Education Policy, 31(2), 226-238.

Steiner-Khamsi, G. (2014). Cross-national policy borrowing: understanding reception and translation. Asia Pacific Journal of Education, 34(2), 153-167.

Swinney, J. (MSP). (2019, May 8). We Want Fully Empowered Teachers. Times Educational Supplement Scotland. Retrieved from https://www.tes.com/news/swinney-we-want-fully-empowered-teachers

Tobbell, J., \& O'Donnell, V. L. (2013). The Formation of Interpersonal and Learning Relationships in the Transition from Primary to Secondary School: Students, Teachers and School Context. International Journal of Educational Research, 59, 11-23.

Treanor, M. (2016). The Effects of Financial Vulnerability and Mothers' Emotional Distress on Child Social, Emotional and Behavioural Well-Being: A Structural Equation Model. Sociology, 50(4), 673-694.

Treanor, M. (2017). Can we put the Poverty of Aspirations Myth to Bed now? In L. Kelly (Ed.), CRFR Research Briefing (Vol. 91). Edinburgh: Centre for Research on Families and Relationships, University of Edinburgh.

UNICEF Office of Research. (2016). Fairness for Children: A League Table of Inequality in Child Well-Being in Rich Countries. UNICEF Innocenti Report Card 13. Florence: UNICEF Office of Research - Innocenti. Retrieved from https://www.unicef-irc.org/publications/830-fairness-for-children-a-leaguetable-of-inequality-in-child-well-being-in-rich-countries.html

UNICEF Office of Research. (2017). Building the Future. Children and the Sustainable Development Goals in Rich Countries Innocenti Report Card 14 (Vol. 14). Florence: UNICEF Office of Research - Innocenti. Retrieved from https://www.unicef-irc.org/publications/890-building-the-future-children-andthe-sustainable-development-goals-in-rich-countries.html

United Nations. (1994, 7-10 June). The Salamanca Statement and Framework for Action. Paper presented at the World Conference on Special Needs Education: Access and Quality, Salamanca, Spain. Retrieved from https://unesdoc.unesco.org/ark:/48223/pf0000098427 
Wilkinson, R., \& Pickett, K. (2018). The Inner Level: How more Equal Societies Reduce Stress, Restore Sanity and Improve Everyone's Wellbeing. UK: Penguin Random House.

Williams, J. M., Bryan, J., Morrison, S., \& Scott, T. R. (2017). Protective Factors and Processes Contributing to the Academic Success of Students Living in Poverty: Implications for Counselors. Journal of Multicultural Counseling and Development, 45(3), 183-200.

Wolff, J., Lamb, E., \& Zur-Szpiro, E. (2015). A Philosophical Review of Poverty. York: Joseph Rowntree Foundation. Retrieved from https://www.jrf.org.uk/report/philosophical-review-poverty

World Health Organisation. (2013). Mental Health Action Plan 2013 - 2020. Geneva, Switzerland. Retrieved from https://www.who.int/mental_health/publications/action_plan/en/

World Health Organisation. (2016). Growing Up Unequal: Gender and Socioeconomic Differences in Young People's Health and Well-Being: Health Behaviour in School-Aged Children (HBSC) Study: International Report from the 2013/2014 survey (Vol. Health Policy for Children and Adolescents, no. 7). Denmark: World Health Organisation. Retrieved from http://www.euro.who.int/en/publications/abstracts/growing-up-unequal.-hbsc2016-study-20132014-survey

Notes

\footnotetext{
${ }^{\mathrm{i}}$ From this point on, the term children will be used to represent both children and young people (adolescents) unless the context is specific to adolescents only.

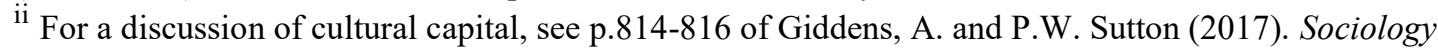
( $8^{\text {th }} E d$.), Cambridge: Polity Press

iii In the current financial year, $£ 120$ million is directed towards the Pupil Equity Fund; $£ 50$ million to the Challenge Authorities and Schools Programme; $£ 8$ million to Care Experienced Children and Young People; and additional funding directed towards National programmes such as the establishment of Regional Collaboratives (https://www.gov.scot/policies/schools/pupil-attainment/)

iv For further information, refer to Education Scotland website

${ }^{v}$ A range of terms within the literature tend to be used interchangeably - mental health difficulty/condition/problem/issue/illness/disorder - with mental illness tending to refer to a diagnosable psychiatric condition and mental health disorder applied to more severe, enduring conditions, such as eating disorders (R. Murphy, 2016).

${ }^{v i}$ The Scottish Index of Multiple Deprivation is devised from a synthesis of 39 data sources which span across domains such as income, employment, health, education, housing, access and crime vii Children in Scotland. (2014). Ask the children what they want: involving children and young people in the development and implementation of improvements to enhance school food provision. Children in Scotland: Edinburgh. www.childreninscotland.org.uk/publications-and-resources/reports/ask-thechildren-what-they-want

viii The SCQF (Scottish Credit Qualification Framework) has twelve levels of attainment from 1-12 (where 12 is the equivalent of doctorate). Level 4 is the equivalent of GCSE (grades D-G) in England and Wales: Level 5 is the equivalent of GCSE (grades A* - C); and Level 6 the equivalent of GCSE AS and A level. Derived from the UK Qualification Comparison Chart.

ix This data has not been replicated in subsequent pupil censuses by the Scottish Government

${ }^{\mathrm{x}}$ Unfortunately, this is an area which has not attracted attention in Scotland from academia. A search on ERIC, using the terms 'social media' + 'Scotland' + 'children' did not elicit a single paper specific to Scotland.

${ }^{x i}$ There is little differentiation within the literature between the use of terms such as belongingness, connectedness, relatedness and sense of affiliation
} 
${ }^{x i i} A$ replication of the study in six clusters of secondary and primary schools in two local authorities in Scotland identified similar findings. These findings have yet to be published. In both studies, postintervention, the differential between support group pupils and their peers reduced and were of less statistical significance across all measures. 